\title{
A Delphi Study of RFID Applicable Business Processes and Value Chain Activities in Retail
}

\author{
Mithu Bhattacharya', Irene Petrick²,Tracy Mullen³, Lynette Kvasny ${ }^{4}$
}

\begin{abstract}
For this research we use Delphi technique to identify the key business processes and value chain activities that are improved by RFID. Our Delphi study involves 74 experts from different domains such as consulting, retail, academia, and third party service providers. We also explored whether there is any difference in expert perceptions about RFID applicable business processes and value chain activities across different business associations.
\end{abstract}

Keywords: RFID; Delphi; retail; business processes; value chain activity.

\footnotetext{
I 32 I D Information Sciences and Technology Building, College of Information Sciences and Technology, The Pennsylvania State University University Park, PA 16802, USA, Ph: 814-867-2768. Email: mubl66@psu.edu

2 I0I T Information Sciences and Technology Building, College of Information Sciences and Technology, The Pennsylvania State University University Park, PA 16802, USA, Ph: 8I4-863-7I33. Email: ipetrick@ist.psu.edu

${ }^{3}$ I 02 F Information Sciences and Technology Building, College of Information Sciences and Technology, The Pennsylvania State University, University Park, PA 16802, USA, Ph: 8I4-865-6425. Email: tmullen@ist.psu.edu

${ }^{4} 329 \mathrm{C}$ Information Sciences and Technology Building, College of Information Sciences and Technology, The Pennsylvania State University University Park, PA 16802, USA, Ph: 8I4-865-6458. Email: lkvasny@ist.psu.edu
} 


\section{Introduction}

Modern retail industry still faces a number of challenges that have not eliminated by the introduction of technologies like barcodes. These issues include:

I) Out of stock situation is a big problem for the retail industry. Average out-of stock level for the retail industry is $8.3 \%$ (Gruen et al., 2002).

2) Inventory inaccuracy leads to huge losses for retailers. According to the case study results with a US based retailer Raman (2000) claimed that there was inaccurate inventory for over $70 \%$ of the stock keeping units in the store.

Radio Frequency Identification (RFID) is an example of automatic identification technology which is much more advanced than the barcode technology and can address these issues effectively. This research work deals with the usage of RFID technology across the retail value chain. RFID adoption rolled out with large retailers such as Wal-Mart, Tesco, and Metro and government agencies such as DOD (US department of defense) and FDA (Food and Drug Administration) mandating their suppliers to tag their products at a pallet or case level with the objective of streamlining their value chain processes. Real-time visibility could be a reality with RFID which was not possible with the use of bar-code technology.

Given the early stage of RFID adoption, there is a lot of uncertainty regarding the actual value and return on investments (ROI) of the technology. In other words there is still a large gap between the ideal vision and the current perception of businesses regarding the value of RFID. It is crucial to investigate how RFID can bring value to organizations. Hence, our work seeks to improve the understanding of the value of RFID by discussing the most significant business processes and value chain activities that could be improved by implementing RFID. This would help retailers to situate the potential benefits of RFID within the context of business processes and value chain activities. This can drive RFID adoption in retail considering that most retailers today rank value chain management as their key priority for gaining competitive advantage and also because most of the RFID benefits within the retail sector primarily revolve around allowing for improved value chain management and streamlined business processes through reduced manual intervention and thus errors.
We adapt Rogers' diffusion model (Rogers, 1995) to encapsulate the entire research problem. The various stages in the adapted model are knowledge, persuasion, design and decision, and implementation. Figure I below shows our research model. The knowledge stage involves enhancing the required information about the various aspects of the technology. Issues such as RFID adoption pros and cons, retail domain characteristics, and current RFID adoption status are linked with this stage. The persuasion stage of the diffusion model maps to RFID-adoption drivers and key benefits, and the decision and design stage maps to potential value chain activities, RFID-applicable business processes, and RFID technology choice (in terms of RFID frequency, standards, case/pallet level of tagging, and so on, and finally the implementation stage maps to implementation challenges and diffusion strategy. For this paper, we only focus on the design and decision stage involving and business processes and value chain activities. The other stages and thus related issues are beyond the scope of this paper. The primary reason and justification to choose Roger's DOI as the theoretical foundation for this research is the simplicity of the theory and the stage model (Innovation adoption takes place in different stages) as the building block of the theory. The stage model of the theory is adapted in this research to encompass the research problem. This theory allows us to put all the research aspects into a single framework and use an integrated lens to study them which provides deeper insights. The key idea is that an integrated lens is necessary to study the research issues which are inter-linked.

Although it has been claimed that RFID is going to revolutionize the way businesses are conducted today, the adoption rate of the technology has been relatively slow. This work could guide decision makers and inform consultants about relative importance of how to go forward for future adoption decisions. We used Rogers' technology diffusion model to conceptualize the way decision makers and organizations could make decisions about adopting RFID technology.

To guide our investigation and analysis, we use the following research questions:

-Which retail business processes could be optimized by RFID?

- Which retail value chain activities could be optimized by RFID?

- Are there any differences in expert perceptions regarding RFID applicable business processes and value chain activities across different business associations? 


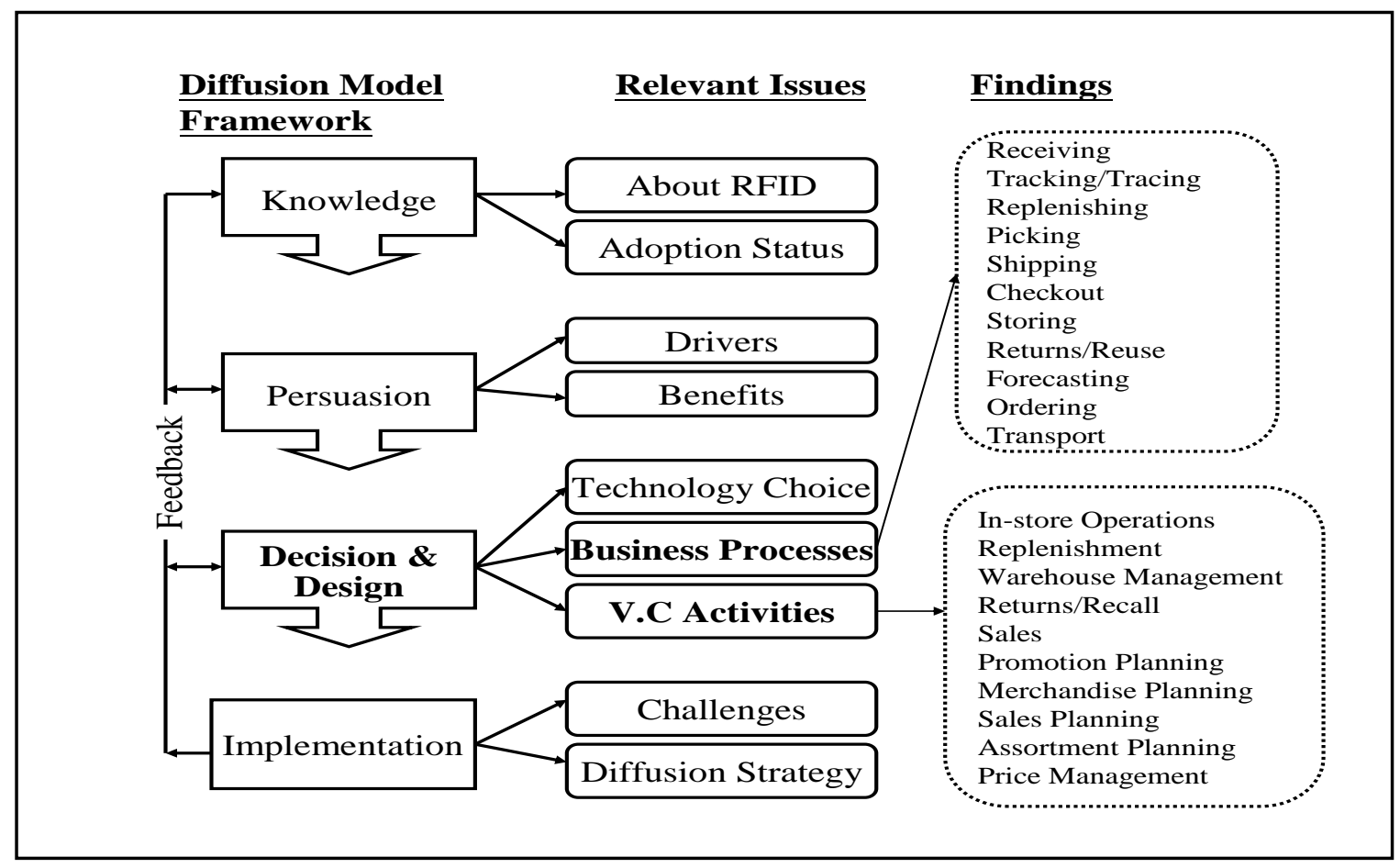

Figure I. Research model

In the next section we present the theoretical foundation followed by research methodology. Then we discuss related research work and the analytical results and discussion finally followed by conclusions.

\section{Theoretical Foundation}

Past research on advanced technologies suggests that the outcomes of a technology depend more on how it is used by people than the technology itself (DeSanctis and Poole, 1994). Thus the layout of this research work incorporates five distinct patterns that are adoption drivers, benefits, business processes, value chain activities, and implementation challenges. However the focus of this paper is business processes and value chain activities. The main theoretical perspective used as the foundation of this research is Roger's diffusion of innovation. Roger's theory of diffusion of innovation (DOI) is used to investigate the impact of RFID in retail value chains. The core concepts of the theory are briefly discussed below.

\section{Roger's Diffusion of Innovation Model}

Diffusion is the process by which an innovation that could be a new technology communicates through certain channels over time among the members of society. The diffusion of innovation is considered to be the first theory about technology acceptance. Everett Rogers formalized the theory in his book Diffusion of Innovation (1995). Rogers categorizes system member innovativeness into five categories where innovativeness defines the degree to which a member is relatively earlier in adopting new technology than other members. These categories are: innovators, early adopters, early majority, late majority, and laggards. Innovators are thought to be up to date with cutting edge technologies and have the ability to gain information from multiple sources as well as having the nature to take risks. Early adopters are deliberate members with many informal social contacts that use the data provided by the innovators to make their individual adoption decisions. Early majority are members who deliberate for sometime before completely adopting a new idea. They adopt new ideas just before the average 
member of a system. Late majority is classified as the skeptics and traditionalists and conforms to the opinion leaders decision but a little late because of uncertainties. Finally, laggards are classified as those who are either very traditional or are isolated from the social system and take much longer than average to adopt new innovations.

Rogers proposed a five-stage model of innovation adoption and implementation in enterprises. He defined the adoption process as "the process through which an adopter unit passes first knowledge of an innovation, to forming an attitude toward the innovation, to a decision to adopt or reject, to implementation of the new idea, and to confirmation of this decision." In particular, Rogers (1995) argued that the decision to adopt and use unfolds in the following five stages that are interlinked with each other. These stages are:

- Knowledge: In this stage, a member becomes aware of the existence and uses of an innovation.

- Persuasion: In this stage, a member forms a favorable or unfavorable attitude toward the innovation.

- Decision: In this stage, a member engages in activities that lead to making a choice of adopting or rejecting the innovation.

- Implementation: In this stage, a member actually begins using the innovation.

- Confirmation: Finally this stage determines whether the member accepts or rejects the innovation.

We used Rogers' diffusion of innovation model to develop the research framework of this research. With the guidance of the theory we put the issues (drivers, benefits, business process, value chain activities, and challenges) into an integrated perspective. The idea is to extend Roger's model specifically into the context of RFID implementation that will potentially serve as a framework for future research works to study the impact of RFID and other automatic identification technologies in general. Information about the technological characteristics and the status of adoption of the RFID technology relates to the knowledge stage of the diffusion model. The persuasion stage pertains to knowledge about the adoption drivers and potential benefits of the technology. Information related to business processes, value chain activities, and the choice of technology contributes to the design and decision stage of Roger's diffusion model and finally challenges for implementation and the diffusion strategy contributes to the final stage of implementation in the general model. The various stages of the diffusion model are inter-related and are connected via feedback loop. Thus we argue that these issues are also inter-linked and cannot be studied standalone. For this paper we focus only on the design and decision stage.

\section{Research Method}

We used 'Delphi method' for our research work. Delphi method is a well established scientific method that is widely used in Information Science (IS) research and is suitable to meet our research objective. The methodology is briefly discussed below.

\section{Delphi Technique}

Delphi technique is a method to combine the informed judgments from a panel of independent experts. This method is relevant when no or very little hard data or well-established theory is available, but experts have relevant information about the focus of the research. It is a procedure that is based on the premise that aggregation reduces the error of individual responses. The method is well established and dates back to the 1959s, developed by a team of researchers named Dalkey and Helmer. According to Dalkey (1969) the Delphi method has three primary features which are anonymity, controlled feedback and iteration, and formal group judgment. Each respondent submits his own independent answer to the relevant questions in the interview/questionnaire. The rationale behind the anonymity feature is that anonymity restricts possible bias that could arise from peer pressure or dominant individuals. The results of a given round of responses are summarized and reported to the group who are then asked to reassess their replies in light of the feedback. The premise is that iteration with feedback allows interchange among the members of the group in a controlled manner. Finally, the group answer is presented as a formal aggregation given the final set of individual answers. The group judgment may be formulated as the mean or median of the responses. The formal aggregation allows for a well-defined and well-represented group response thus eliminating individual error of responses.

These results from the Delphi study can spotlight key RFID adoption issues with the potential to maximize usage and thus benefits. In this study we used two iterations in the Delphi study. The findings can guide future research work on this area and can also be used to draw managerial implications that are crucial for widespread adoption of the RFID technology. 


\section{Candidate Selection}

In order to reduce bias from a group composed of candidates of similar backgrounds, we obtained candidates from different sectors such as consulting, academia (faculty researchers), retail, and third party service providers. This allowed achieving a broad overview and eliminating inherent bias within each sector. The fundamental characteristics and qualifications required for candidates are: history of association with RFID projects either at management, operational, or research level, individuals who are viewed as experts and are self motivated and forward thinking.

The Delphi study was conducted online between December 2009 and January 2010. After the questionnaire was developed it was sent to around 240 experts in electronic format through email. The web address of the questionnaire was provided in the email. The experts were identified through personal contacts. Two weeks later an email reminder was sent to request to participate in the research study and respond to the questionnaire. After another two weeks we received around 80 responses, out of which 74 were deemed usable. The response rate is $30.84 \%$ which is a significantly high number and could be explained by the use of personal contacts and personalized methods to contact the candidates. After another two weeks we sent out the summary results to each expert candidate giving them an opportunity to change their responses in light of the amalgamated results. Delphi based rounds continue until a predetermined level of consensus is reached or no new information is gained. In this study, not much new information is gained after the second round and thus no follow up rounds were conducted. According to (Altschuld, 1993) two iterations are usually enough to obtain good estimate of the distribution and consensus view of participants and often not enough new information is gained to warrant the cost of more rounds. The responses from the two rounds were merged together at the end of the study to create the final data set for analysis for this study.

We had a total of 74 expert candidates, including consultants $(23 ; 31.1 \%)$, academics $(17 ; 23 \%)$, retail practitioners (16;21.6\%), and third-party service providers (I8; 24.3\%). We also attempted to obtain the opinions of experts across the spectrum of management levels. Among our expert candidates, 28 (37.8\%) held top management positions, 8 (10.8\%) IT management positions, 19 (25.7\%) were executives, and $19(25.7 \%)$ held research positions. The reason for having a larger sample of experts in this study is to include a breadth of expertise from various business associations to avoid potential biases inherent in a particular sector.

About 44 (59.5\%) of the experts claimed that they have very good knowledge about RFID and 26 (35.1\%) claimed that they know all about RFID. Finally 29 (39.7\%) out of the 74 candidates have greater than five years of involvement with RFID projects, 22 (30.1\%) have 3-5 years of involvement, 14 (19.2\%) have I-3 years of involvement, and 8 (II\%) have less than one year of involvement with RFID projects. Table I below shows the details of the participating experts.

\begin{tabular}{|c|c|c|c|}
\hline B usiness A ssociation & Positions & RFID Familiarity & Involvement \\
\hline Consultant $(23 ; 31.1 \%)$ & Top M anagement (28; 37.8\%) & $\begin{array}{l}\text { Know all about RFID (26; } \\
35.1 \%)\end{array}$ & $>5 Y$ ears $(29,39.7 \%)$ \\
\hline A cademic $(17 ; 23 \%)$ & IT M anagement $(8 ; 10.8 \%)$ & $\begin{array}{l}\text { Good knowledge about RFID } \\
(44 ; 59.5 \%)\end{array}$ & 3-5 Y ears $(22 ; 30.1 \%)$ \\
\hline $\begin{array}{l}\text { Retail Practitioner (16; } \\
21.6 \%)\end{array}$ & Executive Staff $(19 ; 25.7 \%)$ & $\begin{array}{l}\text { Some knowledge about RFID } \\
(4,5.4 \%)\end{array}$ & $1-3$ Y ears $(14,19.2 \%)$ \\
\hline $\begin{array}{l}\text { Third Party Service } \\
\text { Provider }(18 ; 24.3 \%)\end{array}$ & Research $(19 ; 25.7 \%)$ & Not familiar with RFID $(0,0 \%)$ & < 1 Y ear $(8 ; 11 \%)$ \\
\hline Total (74) & Total (74) & Total (74) & $\begin{array}{l}\text { Total (69) Đ5 missing } \\
\text { values }\end{array}$ \\
\hline
\end{tabular}

Table I: Delphi Candidate Details

ISSN: 07 I8-2724. (http://www.jotmi.org) 


\section{Questionnaire Design}

The questionnaire guiding the Delphi study is generated primarily based on the previous research results from content analysis (Bhattacharya et al., 2007, 2008; 2009; 2010a) as well as under the guidance of the fundamental theories that serve as the premise of this work. We have adapted and amalgamated measures from previous studies for ensuring reliability of the study instrument (Premkumar and Roberts, 1999; Ranganathan and Jha, 2005; Sharma and Citurs, 2005)). We also pilot tested the questionnaire with graduate students to enhance clarity and question focus. The questions are designed as 5 point Likert scale (Strongly disagree (I) to Strongly agree (5)). The reliability of the measures was established using Cronbach's alpha to establish inter-item reliability. The Cronbach's alphas were high $(0.916$ for business processes; 0.921 for value chain activities). The validity of the measures was established using principal component factor analysis. The items loaded on one factor each for business processes and value chain activities.

\section{Related Research}

Studies of RFID and its applications cover a wide range of adoption characteristics, industry sectors, and geographical regions. Information provided from one entity within the supply chain to the other is the factor that differentiates the value-based supply chain from the traditional linear approach (Markland et al., 1995). Improved information sharing capabilities leading to competitive advantage has caused businesses to invest on enabling automatic identification technologies like bar-codes and RFID and supporting technologies that process the collected data into valuable information. RFID when used in supply chain management can create and sustain a firm competitive advantage (Tajima, 2007).

Many supply chain processes can be enhanced using RFID technology. RFID can be implemented into a variety of activities starting from the receipt of raw materials to the delivery of products to customers. Due to the considerably high cost of the RFID technology it can be very expensive to apply the technology to each step in the supply chain. Therefore the major challenge is to investigate individual company practices and determine the processes and activities that will benefit the most from it so that the implementation is opportunistic. In the past few years, RFID technology has been expanding into the areas of tracking video cassettes in rental stores for better inventory management, tracking meat throughout processing facilities to monitor temperatures, and tracking reusable containers as they are transferred between suppliers and manufacturers. The success of these applications has inspired industries to expand the technology across new horizons to better integrate the supply chain so that they are transformed into intelligent, self managing entities (Schmidt, 200I).

The benefits that RFID provide include faster information retrieval, improved supply chain visibility, higher information content, and less probability of loss or theft (Hickey, 1999). Improved supply chain visibility and full or semi automation of rote operations are significant benefits that could be achieved from RFID technology implementation (Bose and Pal, 2005). RFID could significantly reduce out of stock situations for retailers (Bhattacharya et al., 2007; Bhattacharya et al., 2008, 2009; 2010a; Karkkainen and Holmstrom, 2002; Karkkainen, 2003). The technology leads to savings that comes from improved inventory management, reduced employee errors, replenishment productivity, and reduced stock loss (Karkkainen, 2003). Within grocery retailing RFID allows for automated inventory replenishment, improved customer service, reduced stock out situations, and improved information sharing thus leading to a more controlled supply chain resulting from the improved visibility (Prater, 2005). Ranky (2006) suggests that RFID improves tracking and tracing of products and assets across the supply chain for major manufacturers, distributors, and retailers could lead to an integrated supply chain. (Keating et al., 2010) suggests that RFID adopters and non-adopters both are driven by the RFID benefits such as greater data accuracy, improved information visibility, service quality, process innovation, and track-and-trace capabilities. However, an opportunity to derive strategic benefits from RFID through improved decision making is what distinguishes the adopters from the non-adopters.

The business processes that are improved with RFID across a specific supply chain are identified to be receiving and put-away, picking, shipping, and replenishment (Subrina et al, 2003; Wamba, et al., 2007; Bhattacharya et al., 20l0b). Optimization of these processes can be achieved when RFID is used by eliminating or reducing manual interventions that is otherwise needed thus 
contributing to cost savings. RFID aids in the development of new smart business processes triggered by automated events e.g. as soon as a truck leaves the manufacturing facility, an ASN (Advanced Shipping Notice) is sent to the distribution centre via the EPC (Electronic Product Code) and also allowing transit visibility through GPS (Geographical Positioning System) tracking between the manufacturer and the distributor. RFID also allows merging of both intra and inter-organizational business processes. As an example of intra-organizational process integration, receiving and put-away processes could be merged by RFID by automatically linking in-coming product information to dedicated shelves in the warehouse thus reducing the need for staging areas. As an example of inter-organizational process integration, the shipping process at the manufacturer end could be integrated with the receiving process at the retailers' end by linking incoming physical and digital RFID tag products to digital information (ASN) received through EPC network from the manufacturer.

\section{Measuring the Impacts of IT}

Researchers suggest that information technology (IT) creates business value along three dimensions that lead to automational, informational, and transformational effects (Mooney et al., 1996; Dedrick et al., 2003). These effects are briefly discussed below:

I. Automational: This effect enhances efficiency by automating operational processes that need manual interventions and are subject to errors.

2. Informational: This effect leads to increased performance by achieving improved capabilities to collect, store, process, and disseminate information which can lead to better decisions and thus improved quality.

3. Transformational: This effect refers to the role of IT in facilitating process reengineering and redesigning organizational structures (Mooney et al., 1996).

As an example in the context of RFID technology, the technologycan eliminatetimeformanual countingofnumber of cases, pallets, or cases on a pallet (automational effect), reduce the number of shipping errors (informational), and change manual replenishment process of stock from backroom inventory to shop floor (transformational).

Many studies suggest that IT investments drive changes in business processes. For example, (Subirana et al.,
2003) used a business process based approach to estimate the impact of RFID technology on warehouse management processes. They suggest that the effect of RFID technology reduces the time to complete receiving process, improves the quality of the shipped orders in the shipping and handling processes, and reduces labor costs of warehouse processes. They also suggest that use of RFID in one process can potentially improve other related processes due to interdependencies in processes. For example, verifying cases in the receipt process has an impact in the accuracy of the put away process.

(Kohli and Sherer, 2002) also suggest that supply chain entities need to make major changes in their business processes to fully capture the benefits from IT investments in the supply chain. This approach is called a process based approach to studying the impact of an information technology. It is a useful and ideal approach to understanding the impact of RFID because it allows studying the impact at a more detailed level and thus allows capturing wider potential of the technology (Wamba et al., 2008). We have used a similar approach in this research work with the goal to better capture the impact of RFID. There are other studies which indicate the need for the process-oriented models rather than traditional black box approach to understand the impact of IT (Kriebel, 1989; Barua et al., 1995; Kohli and Sherer, 2002).

\section{Analytical Results and Discussion}

Our analytical results and discussion are framed according to the stage in which they occur in the research model presented in Figure I. We focus on design and decision stage and identify key RFID applicable business processes and value chain activities. First, we will discuss the current RFID adoption status in Retail as perceived by the experts.

\section{Current RFID Adoption Status in Retail}

Retail is the second largest sector in terms of the number of employees as well as the number of establishments for doing business in the United States (Vargas, 2007a, b). Increasing globalization has increased retailer competition, thus motivating companies to attain better performance (Koh et al, 2006, Wamba et al, 2007). Retailers see RFID technology as one potential means of staying competitive and achieving profitability both in the short as well as the long term (Wamba et al., 2006). 
According to IDTechEx (2006), the retail sector will comprise $44 \%$ of the global RFID market value for systems including tags by the year 2016. So far a few large retailers including Wal-Mart, Metro, and Tesco deploy RFID at case and pallet level. Although item-level tagging is the ultimate goal, none of these retailers have still committed to using RFID at this level. Metro was the first to begin roll outs in November 2004 with 20 partners at the pallet level and by 2006 expected to receive RFID tagged shipments from about 300 suppliers covering about $60-80 \%$ of sales (RFID Journal, 2004). Wal-Mart roll out started in January 2005 with its top 100 suppliers at the case and pallet level simultaneously. By January 2006 another 200 suppliers started shipping RFID-tagged cases and pallets to WalMart. Initial process change that Wal-Mart expected to realize was automatic generation of picking lists for store employees for those products available in the backroom (RFID Journal, 2005). Metro begun RFID roll out by the end of the year 2004 to track shipments from its central distribution center to 98 of its Tesco Extra super stores in UK (RFID Journal, 2004). They also rolled out RFID internally to track reusable trays as part of their secure supply chain initiative. Despite all the early uproar about going RFID, the adoption of the technology in retail has slowed down. This demands the need to investigate the perceived RFID adoption status by experts in the area.

From the Delphi study we captured the experts' perception about the current status of RFID adoption in retail sector. According to the experts complying with trading partner requests or government mandates (slap and ship approach) is where the RFID adoption status currently lies. Next is the optimization achieved by improved efficiencies of specific current processes within the retail organization (comprising the value chain). Finally experts also pointed that RFID adoption status is at the level of transformation achieved when new processes and applications come up due to RFID capabilities. We observed that the experts considered all the three conditions currently governing the RFID adoption status in retail to be closely important. Table 2 below depicts experts' opinion about current RFID adoption status. However looking at the specific numbers we can say that slap and ship still governs RFID adoption followed by optimization and, transformation. However transformation is where the real benefit of RFID is. For example, RFID technology can change manual replenishment process of stock from backroom inventory to shop floor inventory thus reducing out of stock situations and safety stock requirements leading to cost savings for businesses (transformational).

\begin{tabular}{|lc|}
\hline A doption Status & Rating A verage \\
\hline Slap and ship & 3.73 \\
Optimization & 3.67 \\
Transformation & 3.62 \\
\hline
\end{tabular}

Table 2. Current RFID Adoption Status in Retail

\section{RFID Applicable Business Processes}

Table 3 below shows the II retail business processes that the experts perceive to be significantly improved by the use of RFID. However these business processes are not exclusive to retail. From the Delphi study results we found out that receiving is one of the most important business processes for retailers that could be improved by the use of RFID. The other important business processes that could be improved are tracking and tracing, replenishing, picking, and shipping. Next are checkout, storing, reuse and recycle / returns, demand forecasting, ordering, and transport. Use of RFID for the receiving, picking, shipping, and storing business processes allows for reduced manual intervention from employees and thus reduces errors. Reducing such errors can then reduce stock out situations which is a big problem for retailers. Use of RFID for tracking and tracing of products across the value chain provides retailers with accurate information about the whereabouts of products in real time and thus save them money from reordering of products which are delayed but are on the way. This is an informational benefit for the retailers. RFID can also improve the replenishing process by allowing for just in time inventory thus leading to reduced inventory and also reduced out of stock situations. It also eliminates the need for physical inventory counts. This can again lead to a huge cost savings for retailers. RFID can allow for automatic checkout by customers thus reduce the requirement of labors to facilitate the checkout process. This could improve customer service since the customers can save a lot of their time standing in checkout queues.

RFID can facilitate reuse and recycle / returns process significantly. By the use of RFID, managing reusable assets like crates can be made simple and streamlined. This could lead to reduced loss of resources and thus lead to savings in long term. The technology can also improve the returns process by allowing retailers to gain far greater insights into their overall returns process through instant access to purchase data. They can track the returns by 
manufacturer, store, dates of sales, and consumer. They can share these data with CPG (Consumer Product Goods) makers and thus both parties can better monitor returns processes and gain insights into patterns that may emerge through processing the data across regions and retailers.

RFID can improve the transport process by allowing visibility into the location of the trailers and the cargo they contain, and also offering status alerts in the event that a trailer is opened while in transit.

RFID also improves the demand planning process by allowing retailers to respond to consumer demand fast and also marketing to consumers in stores with a fast and responsive value chain. With such timely information, on shelf availability of products is improved tremendously which can then increase customer satisfaction.

Finally the ordering process is improved by RFID by allowing for an informative ordering for products through the 'right now' ability to see what is truly in stock thus enabling a rapid reaction to inventory demand and current stock levels. Most of the business processes that the experts think will be improved through RFID usage revolve around providing for benefits that could be achieved through the automational effect of the technology (less manual intervention). However the real potential of the technology is the transformational effect which could be achieved when RFID triggers new business processes to be created that could change the way retailers do business today.

\begin{tabular}{|lc|}
\hline Business Processes & Rating A verage \\
\hline Receiving & 4.40 \\
Tracking and tracing & 4.30 \\
Replenishing & 4.25 \\
Picking & 4.10 \\
Shipping & 4.05 \\
Checkout & 4.01 \\
Storing & 3.81 \\
Re-use and recycle/Returns & 3.76 \\
Transport & 3.74 \\
Demand forecasting & 3.68 \\
Ordering & 3.68 \\
\hline
\end{tabular}

Table 3: RFID Applicable Business Processes
Factor analysis of the initial II items of RFID applicable business processes revealed a single factor with Eigenvalue above 1.0 that account for about $56 \%$ of the total variance. Specific factor loadings are shown in Table 4. 


\begin{tabular}{|lccc|}
\hline \multicolumn{1}{|c}{ Factors and Items } & Factor L oadings & Eigen-V alue & $\%$ of V ariance \\
\hline RFID applicable business processes & & 6.058 & 55.069 \\
- $\quad$ Picking & 0.808 & & \\
- $\quad$ Transport & 0.808 & \\
- $\quad$ Demand forecasting & 0.792 & \\
- & Shipping & 0.789 & \\
- Storing & 0.781 & \\
- $\quad$ Replenishing & 0.758 & \\
- & Reuse and recycle / Returns & 0.719 & \\
- Tracking and tracing & 0.697 & \\
- & 0.683 & \\
\hline
\end{tabular}

Table 4. Factor Analysis of RFID Applicable Business Processes

\section{RFID Applicable Value Chain Activities}

Table 5 below shows the value chain activities that the experts believe are significantly improved by RFID. According to the Delphi study results improvement in in-store operations is the most important RFID applicable value chain activity. The other important value chain activities that could be enhanced by RFID usage are replenish and scheduling, warehouse management, returns / recalls, and sales followed by promotion, merchandise, sales, and assortment planning, and finally price management.

RFID technology improves store operations and increases shelf availability by allowing for tracking of goods throughout the facility, including in the back room, on the selling floor, in the fitting rooms and at the point of sale. This visibility enables retailers to optimize their inventory replenishment, reduce out-of-stocks and onhand inventory and, ultimately, improve sales. RFID improves the replenishment activity by allowing improved management of product delivery thus avoiding out-ofstock situations. RFID has dramatically improved the warehouse management activity by allowing for effective management of inventory and track the location of specific goods within the warehouse. RFID also improves the returns / recalls activity by enabling better management of return merchandise. Sales activity is improved by increasing revenue generation through reduced labor needs for finding products for customers. The employees can rather focus on customer interaction thus boosting customer satisfaction which is crucial for retailers as it provides a competitive edge.

\begin{tabular}{|lc|}
\hline V alue Chain A ctivities & Rating A verage \\
\hline In-store operations & 4.38 \\
Replenish, allocation, and scheduling & 4.23 \\
Warehouse management and distribution & 4.15 \\
Returns/ Recall & 3.84 \\
Sales & 3.75 \\
Promotion planning & 3.75 \\
M erchandise planning & 3.71 \\
Sales planning & 3.57 \\
A ssortment planning & 3.56 \\
Price management & 3.52 \\
\hline
\end{tabular}

Table 5. RFID Applicable Value Chain Activities 
RFID can also improve retail planning activities. The technology can allow improved planning of promotions based on real time sales data. It can also improve the merchandise planning activity by enabling planning and maintaining a balance between sales and inventory. Sales planning activity could be improved by aiding in planning routes to better reach target customers. This is achieved through personalized guidance that can be provided to the valued customers based on their based on the other products that they have purchased in past or are looking at that moment. For example the customer could be prompted to buy some accessories that match with the suit that she is trying or has already purchased. Assortment planning activity could be improved by allowing a better selection of merchandise for a variety of customer needs. Finally the price management activity could be improved through RFID usage through improved pricing decisions based on forecast data generated from real-time information. All this is possible through the real time visibility that RFID provides to the retailers.

Although the experts perceive the planning activities to be potentially improved through RFID usage, however in reality most retailers are mostly focusing on the most obvious activities at the bottom end of the value chain such as in-store operations, replenishment and so on. The real potential needs retailers to go beyond the obvious and start tapping onto other value chain activities that are on the top end of the value chain. The experts perceive those activities to be almost equally applicable to RFID usage.

Factor analysis of the initial 10 items of RFID applicable value chain activities revealed a single factor with Eigenvalue above 1.0 that account for about $60 \%$ of the total variance. Specific factor loadings are shown in Table 6.

\begin{tabular}{|lccc|}
\hline \multicolumn{1}{|c}{ Factors and Items } & Factor L oadings & Eigen-V alue & \% of V ariance \\
\hline RFID applicable value chain activities & & 5.903 & 59.026 \\
- M erchandise planning & 0.889 & & \\
- Price management & 0.851 & \\
- A ssortment planning & 0.836 & \\
- Rales & 0.798 & \\
- Replenishment & 0.760 & \\
- Rales planning & 0.727 & \\
- Weturns / Recall & 0.726 & \\
- In-store operations & 0.715 & \\
- Promotion planning management and distribution & 0.690 & \\
\hline
\end{tabular}

Table6. Factor Analysis of RFID Applicable Value Chain Activities 


\section{Comparison of Expert Perceptions across Business Association}

After we identified the most significant business processes and value chain activities that could be improved by RFID we wanted to see if there is any difference in expert perceptions based on their field of business association such as consulting, academia, retail, or third party service providers. This could give some deeper insights on the current RFID adoption status and also act as a pointer to future research initiatives.

We did some exploratory statistical analysis of the data to look for general patterns. We performed different statistical tests including multivariate analysis of variance (MANOVA) and multiple one way analyses of variance (ANOVA) on the business processes, and value chain activities data across the expert's business associations. The justification for conducting the MANOVA tests is that we have multiple dependent variables each for business processes and value chain activities and we intended to examine the differences between the levels of the independent variable (Business association) as a function on combination of dependent variables (different business processes and value chain activities). The justification for performing multiple ANOVA tests is that this research is exploratory and also because the dependent variables are conceptually independent of each other i.e. they do not measure the same thing (Biskin, 1980). We intend to study the effect of business association of experts on their perceptions about applicability of RFID for business processes and value chain activities to reach some tentative non-confirmatory conclusions. We only performed the univariate ANOVA tests for the main effect that we found significant in the MANOVA test. Since this is an exploratory study we used a significance level of $10 \%$ to capture any pattern that is close to being significant. Our goal is to draw optimal insights from the data analysis.

\section{Multivariate Analysis of Variance (MANOVA) Results}

First we conducted a 4 (Business Association) $X$ II (Business Processes) multivariate analysis of variance (MANOVA) to test whether the four groups (Academia, Consulting, Retail, and Third Party Service Providers) are statistically different from each other in terms of their perceptions about RFID applicability for business processes.

Our null hypothesis is:

$\mathrm{HI}_{0}$ : Perceptions about RFID applicability for business processes do not vary as a function of the business association of the experts.

The analysis revealed a non-significant main effect for business association. The calculated Wilks' Lambda $=0.582, \mathrm{~F}(33,172)=1.05, \mathrm{p}$-value $=0.404(>0.10)$, and partial eta squared $=0.165$. Since $p$-value $>0.10$, we cannot reject the null hypothesis $\mathrm{HI}_{0}$ at $10 \%$ significance level and conclude that the expert perceptions about RFID applicability for business processes do not vary as a function of the expert business associations.

Next we conducted a 4 (Business Association) $\times 10$ (Value Chain Activities) multivariate analysis of variance (MANOVA) to test whether the four groups (Academia, Consulting, Retail, and Third Party Service Providers) are statistically different form each other in terms of their perceptions about RFID applicability for value chain activities. Our null hypothesis is:

$\mathrm{H}_{0}$ : Perceptions about RFID applicability for value chain activities do not vary as a function of the business association of the experts.

The analysis revealed a significant main effect for business association. The calculated Wilks' Lambda $=0.522, \mathrm{~F}(30$, $17 \mathrm{I})=1.4 \mathrm{II}, \mathrm{p}$-value $=0.090(<0.10)$, and partial eta squared $=0.195$. Since $p$-value $<0.10$ we reject the null hypothesis $\mathrm{H}_{2}$ at $10 \%$ significance level and conclude that the expert perceptions about RFID applicability for value chain activities varies as a function of the expert business associations. Table 7 below shows the results of the MANOVA tests. 


\begin{tabular}{|c|c|c|c|c|}
\hline Hypotheses & $\begin{array}{l}\text { WilkÖ } \\
\text { Lambda }\end{array}$ & $\begin{array}{c}\mathrm{F}- \\
\text { Values }\end{array}$ & $\begin{array}{c}\text { P- } \\
\text { Values }\end{array}$ & Results \\
\hline $\begin{array}{l}\mathrm{H} 1_{0}: \text { Perceptions about RFID applicability for business processes do not vary } \\
\text { as a function of the business association of the experts. }\end{array}$ & 0.582 & 1.050 & 0.404 & $\begin{array}{l}\text { Cannot } \\
\text { reject } \mathrm{HI}_{0}\end{array}$ \\
\hline $\begin{array}{l}\text { H } 21_{1} \text { : Perceptions about RFID applicability for value chain activities do not } \\
\text { vary as a function of the business association of the experts. }\end{array}$ & 0.522 & 1.411 & $0.090 *$ & R eject $\mathrm{H} 2_{0}$ \\
\hline
\end{tabular}

Table 7. MANOVA Results: Expert Perception Comparison / * Significant at 10\% significance level

\section{Univariate Analysis of Variance (ANOVA) Results}

Since the main effect of business association is significant for value chain activities we decided to look at the univariate ANOVA tests of the main effect.

Univariate effects for Value Chain Activity I (Replenishment):

$\mathrm{H}_{0}: \mu$ Academia $(\mathrm{VCl})=\mu$ Consulting $(\mathrm{VCl})=\mu$ Retail $(\mathrm{VCl})=\mu$ Third Party Service Providers (VCI)

The calculated test statistic is $\mathrm{F}(3,69)=2.966, \mathrm{p}$-value $=$ $0.038(<0.10)$ and thus we reject the null hypothesis $\mathrm{H}_{0}$.

Hence the univariate analysis for perceptions about applicability of RFID for replenishment activity revealed a significantmain effectforbusinessassociation withacademic experts $(M=4.3529$, S.E $=0.12820)$ reporting more favorable perception followed by consultants $(M=4.3182$, $S . E=0.15270)$, third party service providers $(M=4.5556$, $S . E=0.18475)$, and finally retail $(M=3.8125, S . E=0.22765)$.

Univariate effects for Value Chain Activity 2 (Warehouse management):

$\mathrm{H}_{0}: \mu$ Academia $(\mathrm{VC2})=\mu$ Consulting $(\mathrm{VC2})=\mu$ Retail $($ VC2) $=\mu$ Third Party Service Providers (VC2)

The calculated test statistic is $\mathrm{F}(3,68)=0.812$, $\mathrm{p}$-value $=$ $0.492(>0.10)$ and thus we cannot reject the null hypothesis $\mathrm{H} 4{ }_{0}$. Hence the main effect for business association is not significant and we conclude that the expert perceptions about RFID for warehouse management do not vary across business associations.
Univariate effects for Value Chain Activity 3 (In-store operations):

$\mathrm{H}_{0}: \mu$ Academia $(\mathrm{VC} 3)=\mu$ Consulting $(\mathrm{VC} 3)=\mu$ Retail $(\mathrm{VC} 3)=\mu$ Third Party Service Providers (VC3)

The calculated test statistic is $\mathrm{F}(3,69)=0.117$, $\mathrm{p}$-value $=$ 0.950 ( > 0.10 ) and thus we cannot reject the null hypothesis $\mathrm{H} 50$. Hence the main effect for business association is not significant and we conclude that the expert perceptions about RFID for in-store operations do not vary across business associations.

Univariate effects for Value Chain Activity 4 (Sales planning):

H6: $\mu$ Academia $($ VC4) $=\mu$ Consulting $(V C 4)=\mu$ Retail $($ VC4) $=\mu$ Third Party Service Providers (VC4)

The calculated test statistic is $\mathrm{F}(3,68)=2.713$, $\mathrm{p}$-value $=$ $0.052(<0.10)$ and thus we reject the null hypothesis $\mathrm{H} 3_{0}$.

Thus the univariate analysis for perceptions about applicability of RFID for sales planning revealed a significant main effect for business association with consultants ( $M$ $=3.95, \mathrm{~S} . \mathrm{E}=0.15)$ reporting more favorable perception followed by third party service providers $(M=3.55, S . E$ $=0.17)$, academics $(M=3.4 I, S . E=0.2 I)$, and finally retail $(M=3.20, S . E=0.28)$.

Univariate effects for Value Chain Activity 5 (Sales):

$\mathrm{H}_{0}: \mu$ Academia $(\mathrm{VC5})=\mu$ Consulting $(\mathrm{VC5})=\mu$ Retail $($ VC5) $=\mu$ Third Party Service Providers (VC5) 
The calculated test statistic is $\mathrm{F}(3,69)=1.371, \mathrm{p}$-value $=$ $0.259(>0.10)$ and thus we cannot reject the null hypothesis $\mathrm{H} 7$. Hence the main effect for business association is not significant and we conclude that the expert perceptions about RFID for sales activity do not vary across business associations.

Univariate effects for Value Chain Activity 6 (Returns / Recall):

H8 $8_{0}$ $\mu$ Academia $(\mathrm{VC} 6)=\mu$ Consulting $(\mathrm{VC} 6)=\mu$ Retail $($ VC6) $=\mu$ Third Party Service Providers (VC6)

The calculated test statistic is $F(3,69)=0.679, \mathrm{p}$-value $=$ $0.568(>0.10)$ and thus we cannot reject the null hypothesis $\mathrm{H} 80$. Hence the main effect for business association is not significant and we conclude that the expert perceptions about RFID for returns / recall activity do not vary across business associations.

Univariate effects for Value Chain Activity 7 (Promotion planning):

H9: $\mu$ Academia $($ VC7 $)=\mu$ Consulting $($ VC7 $)=\mu$ Retail $($ VC7) $=\mu$ Third Party Service Providers (VC7)

The calculated test statistic is $F(3,69)=0.899, \mathrm{p}$-value $=$ $0.446(>0.10)$ and thus we cannot reject the null hypothesis $\mathrm{H} 9_{0}$. Hence the main effect for business association is not significant and we conclude that the expert perceptions about RFID for promotion planning activity do not vary across business associations.

Univariate effects for Value Chain Activity 8 (Merchandise planning):

HI0: $\mu$ Academia $(\mathrm{VC} 8)=\mu$ Consulting $(\mathrm{VC} 8)=\mu$ Retail $(\mathrm{VC} 8)=\mu$ Third Party Service Providers (VC8)

The calculated test statistic is $F(3,69)=0.1432$, $p$-value $=0.241(>0.10)$ and thus we cannot reject the null hypothesis $\mathrm{HIO}_{0}$. Hence the main effect for business association is not significant and we conclude that the expert perceptions about RFID for merchandise planning activity do not vary across business associations.

Univariate effects for Value Chain Activity 9 (Price management):

HII $: \mu$ Academia $($ VC9) $=\mu$ Consulting $($ VC9 $)=\mu$ Retail $($ VC9) $=\mu$ Third Party Service Providers (VC9)

The calculated test statistic is $\mathrm{F}(3,69)=3.767, \mathrm{p}$-value $=$ $0.014(<0.10)$ and thus we reject the null hypothesis $\mathrm{HII}_{0}$.

Thus the univariate analysis for perceptions about applicability of RFID for price management revealed a significant main effect for business association with consultants $(M=3.95, S . E=0.15)$ reporting more favorable perception followed by third party service providers ( $M$ $=3.67, \mathrm{~S} . E=0.24)$, academics $(M=3.35, \mathrm{~S} . E=0.27)$, and finally retail $(M=2.94, S . E=0.25)$.

Univariate effects for Value Chain Activity 10 (Assortment planning):

$\mathrm{HI} 2_{0}: \mu$ Academia $(\mathrm{VClO})=\mu$ Consulting $(\mathrm{VCIO})=\mu$ Retail $(\mathrm{VCl})=\mu$ Third Party Service Providers $(\mathrm{VClO})$

The calculated test statistic is $\mathrm{F}(3,69)=2.231, \mathrm{p}$-value $=$ $0.092(<0.10)$ and thus we reject the null hypothesis $\mathrm{HI}_{0}$.

Thus the univariate analysis for perceptions about applicability of RFID for assortment planning revealed a significant main effect for business association with consultants $(M=3.86, S . E=0.18)$ reporting more favorable perception followed by third party service providers $(M=3.83$, $S . E=0.27)$, retail $(M=3.12$, S.E $=0.0 .27)$, and finally academics $(M=3.29, S . E=0.29)$.

Table 8 below shows the significant univariate analysis of variance ANOVA results that we observed.

\begin{tabular}{|lccc|}
\hline \multicolumn{1}{|c}{ Dependent V ariables } & DF & F-Statistics & P-V alues \\
\hline Sales planning DV alue chain activity 4 & 68 & 2.713 & $0.052^{*}$ \\
Price management- V al ue chain activity 11 & 69 & 3.767 & $0.014^{*}$ \\
A ssortment planning - V alue chain activity 12 & 69 & 2.231 & $0.092^{*}$ \\
\hline
\end{tabular}

Table 8. Significant ANOVA Results: Expert Perception Comparison / * Significant at 10\% significance level 
The results of the multiple ANOVA tests indicate that the perceptions of retail practitioners is overall more conservative than those from other domains like consulting, third party service providers, and academics. This indicates that most retailers are still focusing on a small spectrum of RFID possibilities and not considering a broader perspective. Or on the other hand this could indicate a possible hype around RFID improving value chain activities.

For future research we would like to investigate the differences in perceptions of experts from various domains through in-depth interviews. We would also extend the research and find out differences if any across other control variables such as expert job positions, familiarity with RFID, and length of involvement with RFID.

\section{Conclusion}

The results from this study provide deep insights and enhance the understanding of a wide variety of RFID implementation issues for retail sector. The detailed description of issues in this research will provide decision makers with adequate comprehensive knowledge for making RFID technology implementation decisions based on individual firm needs. This research work will fulfill practitioner's needs to understand the applicability of RFID particularly for retailers. The research model developed could be used as a platform for future research works in the field of RFID implementation.

We identified the retail business processes and the value chain activities that the experts perceive to be significantly improved by RFID usage. The most significant RFID applicable business processes are identified to be receiving, tracking and tracing, and replenishing whereas the most significant RFID applicable value chain activities are in-store operations, warehouse management, and replenishment. We observed that the expert perceptions about RFID applicability for business processes do not vary as a function of the expert business associations.

However we observed that there are differences in expert perceptions about RFID applicable value chain activities based on their business association. In general we found out that retail practitioners have a more conservative perception about RFID applicability value chain activities compared to experts from other domains.

\section{About the Authors}

Mithu Bhattacharya: Mithu Bhattacharya is a PhD. candidate at the college of Information Sciences and Technology. Her research interests include organizational adoption of technology and statistical data analysis. Her dissertation research is on the impact of RFID on retail value chain. She has published her work in peer reviewed conferences and journals such as IEEE RFID, IEEE VL/ HCC, Decisions Sciences Institute (DSI), and Journal of Operations Management Research.

Irene Petrick: Irene Petrick is a professor of practice who has been in the College of IST of Pennsylvania State University since 2003. Prior to joining the IST, she spent three years as an assistant professor of Industrial Engineering. In addition to her professorial activities, she has over 25 years of experience in technology planning, management and product development in both the academic and industrial settings.

She is author or co-author on more than 100 publications and presentations. Petrick specializes in innovation, technology forecasting, digital road-mapping, and systems management. Recently she has been focusing on global collaboration and supply network effectiveness. While remaining a full-time faculty member, Petrick has received the Boeing Welliver Faculty Fellowship (2005), has been a Computer Sciences Corporation (CSC) Faculty Intern on global assignment in India (Summer 2008), Directed the Enterprise Informatics and Integration Center (2007 to 5/2009) and most recently is working as a Faculty Administrative Fellow with Penn State's Office of Economic and Workforce Development (2009; part time collaboration).

Tracy Mullen: Tracy Mullen is an Assistant Professor at the College of IST of Pennsylvania State University Before joining IST, Mullen worked at Lockheed Research and Development from 1987 to 1992 on automatic software synthesis, and at Telcordia Research and Development (formerly Bellcore) from 1999 to 2001 on applications of Internet markets to telecom, such as bandwidth markets. Mullen's research interests include Internet auctions/markets, intelligent agents, multiagent systems, and electronic commerce. She has assisted in teaching courses on data structures and algorithms, discrete math, and software engineering 
at Rutgers University and the University of Michigan. Mullen teaches comparative computer languages at IST.

Lynette Kvasny: Lynette Kvasny is an Associate Professor at the College of IST of Pennsylvania State University. She received her Ph.D. in Computer Information Systems from the Robinson College of Business, Georgia State University. Her research focuses on how and why historically underserved groups appropriate information and communication technologies (ICT). She has designed, implemented and assessed community computing projects in economically challenged neighborhoods in Atlanta, GA and West Philadelphia and Harrisburg, PA. Her current research examines the performance of racial and ethnic identities in virtual communities, ICT education and workforce participation in the African Diaspora, and the influence of racial, class and gender identities on health information seeking and content creation. Kvasny holds herself accountable to praxis, and uses research knowledge to facilitate social justice, and increase political and economic empowerment.

\section{References}

ALTSCHULD, J.W. (1993). Evaluation methods: Principles of needs assessment II, Delphi technique lecture, Department of Educational Services and Research, The Ohio State University, 1993.

BARUA, A. Kriebel, C.H., and Mukhopadhyay, T. (1995). Information technologies and business value: An analytical and empirical investigation, Information Systems Research, 6, I, 3-23.

BhATTACHARYA, M.B., Chu, C.H., Mullen, T. (2007). RFID implementation in retail industry: Current status, issues, and challenges, Proceedings of 38th Annual Meeting of the Decision Sciences Institute, Phoenix, AZ, 217I-2176.

BhATTACHARYA, M.B., Chu, C.H., Mullen, T. (2008). A comparative analysis of RFID adoption in retail and manufacturing sectors, Proceedings of IEEE International Conference on RFID, 16-17 April, 24I - 249.

BhatTACHARYA, M.B., Chu, C.H., Hayya J., Mullen, T. (2009). An exploratory study of RFID adoption in the retail sector, Proceedings of 40th Annual Meeting of the Decision Sciences Institute, New Orleans, LO, 30II-30I6.
BHATTACHARYA, M.B., Chu, C.H., Hayya J., Mullen, T. (2010a). An exploratory study of RFID adoption in the retail sector, Operations Management Research, 3, I-2, 80-89.

BhatTacharya, M., Petrick, I., Mullen, T. (20l0b). A delphi study of RFID adoption for business process and value chain optimization, Proceedings of 4Ist Annual Meeting of Decision Sciences Institute, San Diego, CA, 305I-3056.

BISKIN, B.H. (1980) Multivariate analysis in experimental counseling research, The Counseling Psychologist, 8, 6972.Psychologist, 8, 69-72.

BOSE, I., Pal, R. (2005). Auto-ID: Managing anything, anywhere, anytime in the Supply Chain, Communications of the ACM, 48, 8, 100-106.

DALKEY, N.C. (1969). The delphi method: An experimental study of group opinion, Memorandum RM-5888 pr, Santa Monica, Rand Corporation.

DEDRICK, J., Gurbaxani, V., and Kraemer, K.L. (2003). Information technology and economic performance: A critical review of the empirical evidence, ACM Computing Surveys, 35, I, I-28.

DESANCTIS, G., Poole, M.S. (1994). Capturing the complexity in advanced technology use: Adaptive structuration theory. Organization Science, 5, 2, I2I-I48.

GRUEN, T.W., Corsten, D.S., Bharadwaj, S. (2002). Retail out-of-Stocks: A worldwide examination of extent, causes and consumer responses, Grocery Manufacturers of America, The Food Marketing Institute and CIES - The Food Business Forum.

HICKEY, K. (1999). A diamond in the rough, Traffic World, 258, 5.

IDTECHEX (2006). RFID - Not what it seems. Retrieved March, 2007 from http://www.idtechex.com/products/en/ articles/00000478.asp

KARKKAINEN, M., Holmstrom, J. (2002). Wireless product identification: Enabler for handling efficiency, customization and information sharing. Supply Chain Management: An International Journal, 7, 4, 242-252. 
KARKKAINEN, M. (2003). Increasing efficiency in the supply chain for short shelf life goods using RFID tagging, International Journal of Retail and Distribution Management, 31,10, 529-536.

KEATING, B.W., Coltman, T.R., Wamba, S.F., and Baker, V. (2010). Unpacking the RFID investment decision, Proceedings of the IEEE, 98, 9, 1672-1680.

$\mathrm{KOH}$, C.E., Kim, H.J., Kim, E.Y. (2006). The impact of RFID in retail industry: issues and critical success factors. Journal of Shopping Center Research, I3, I, I0I-II7.

KOHLI, R., and Sherer, S.A. (2002). Measuring payoff of information technology investments: Research issues and guidelines, Communications of the Associations of Information Systems, 9, I/I4, 24I-268.

KRIEBEL, C.H. (1989). Understanding the strategic investmentininformationtechnology, Chapter7, Information Technology and Management Strategy, K. Laudon and J. Turners (Eds.), Prentice-Hall, Englewood Cliffs, NJ.

MARKLAND, R.E., Vickery, S.K., Davis, R.A. (1995). Operations Management, South Western College Publishing, Cincinnati.

MOONEY, J.G., Gurbaxani, V., and Kraemer, K.L. (1996). A process oriented framework for assessing the business value of information technology. The Data Base for Advances in Information Systems, 27, 2, 68-8I.

PRATER, E., Frazier, P.M.R. (2005). Future impacts of RFID on e-supply chains in grocery retailing, Supply Chain Management, Bradford, 10, 2, 134-143.

PREMKUMAR, G., Roberts, M. (1999). Adoption of new information technologies in rural small businesses, International Journal of Management Science, 27, 467-484.

RAMAN, A. (2000). Retail-data quality: Evidence, causes, costs, and fixes, Technology in Society, 22, I, 97-109.

RANGANATHAN, C., Jha, S. (2005). Adoption of RFID technology: An exploratory examination from supplier's perspective. Proceedings of the eleventh American conference on information systems, II-14 August, Omaha, USA, 2195-2199.
RANKY, P.G. (2006). An introduction to radio frequency identification (RFID) methods and solutions, Assembly Automation, 26, I, 28-33.

RFID Journal (2004). Pallet tracking goes high tech.

RFID Journal (2005). Wal-Mart begins RFID process changes.

RFID Journal (2004). Tesco begins RFID rollout.

ROGERS, E.M. (1995). Diffusion of Innovations (4th edition) (Ed.), New York: The Free Press.

SCHMIDT, C. (200I). Beyond the bar code, Technology Review, 104, 2.

SHARMA, A., Citurs, A. (2005). Radio frequency identification (RFID) adoption drivers: A radical innovation adoption perspective, Proceedings of the eleventh American conference on information systems, II-I4 August, Omaha, USA, 1213-1218.

SUBIRANA, B., Eckes C., Herman G., Sarma S. and Barrett M., "Measuring the Impact of Information Technology on Value and Productivity using a ProcessBased Approach: The case for RFID Technologies", MIT Sloan, Working Paper, available: papers.ssrn.com/sol3/ papers.cfm?abstract_id=478582.

TAJIMA, M. (2007). Strategic value of RFID in supply chain management, Journal of Purchasing \& Supply Management, I3, 26I-273.

VARGAS, M. (2007a). Retail industry profile. Retrieved March, 2007 from http://www.retailindustry.about.com/ 38. VARGAS, M. (2007b). Retail glossary of terminology. Retrieved March, 2007 from http:// retailindustry.about.com/od/abouttheretailindustry/a/ glossary.htm

WAMBA, S.F., Lefebvre, L.A., Lefebvre, E. (2006). Enabling intelligent $B$-to-B ecommerce supply chain management using RFID and the EPC Network: A case study in the retail industry. Proceedings of the 8th International Conference on Electronic Commerce, Fredericton, New Brunswick, Canada, 28I-288. 
WAMBA, S.F., Lefebvre, L.A., Lefebvre, E. (2007). Integrating RFID technology and EPC network into B2B retail supply chain: $A$ step toward intelligent business processes. Proceedings of the 8th International Conference on Electronic Commerce, Fredericton, New Brunswick, Canada, 28I-288.

WAMBA, S.F., Lefebvre, L.A., Bendavid, Y., and Lefebvre, E. (2008). Exploring the impact of RFID technology and the EPC network on mobile B2B ecommerce: A case study in the retail industry, International Journal of Production Economics, II2, 641-629. 
J. Technol. Manag. Innov. 20II,Volume 6, Issue 3 